\title{
Detection and Classification of Plant Leaf Disease
}

\author{
Mr. Ashish N. Patil ${ }^{1}$, Miss. Vidya Pawar ${ }^{2}$ \\ Professor, Computer Science \& Engg, DACOE, Karad, India ${ }^{1}$ \\ Student, Computer Science \& Engg, DACOE, Karad, India ${ }^{2}$
}

\begin{abstract}
Plant leaf images is a form of important data and information in biological science. Plant leaf disease affect in both reduction in both in quality and quantity of agriculture products. Automatic plant leaf detection is very important research topic now because our nation's economy is based on an agriculture products. The automatic leaf detection prove number of benefits in monitoring crops and also automatically detect the leaf disease. The developed image processing technique having four steps as below: 1.The input leaf image is first converted into RGB colour transformation structure. 2.Then the green pixels are removed and masked using a specific threshold level. 3.Then the important segments are captured. 4.Finally the statistics is computed. Using this extracted segments the presents leaf disease is evaluated. Database is about 200 plant leaves of 10 different plants are used for experimental results. In India, Farmers are bearing from an issues developing from a few sorts of plant diseases. In some cases plant's specialists are likewise not ready to distinguish the infection that brings about need of acknowledgment of exact sort of sickness and thusly to product ruin if not dealt with at proper time. Thus, we ought to take the upside of accessible innovation in programmed discovery and arrangement of agrarian plants has turned out to be urgent.
\end{abstract}

Keywords: Plant Leaf Disease, colour transformation, segment, Image processing.

\section{INTRODUCTION}

Research in agriculture is aimed towards increasing food quality and productivity with increased profit. Farmers have wide range of diversity to select fruit and vegetable crop. Advanced computing system to identify the diseases using infected images of various leaf spots. Such crops caused by fungi, bacteria, viruses. Diseases management is difficult task. Huge number of disease found on leafs.

The image processing is best way to detecting diseases. Images form important data and information in biological science. The proposed system is a software solution for automatic detection of plant leaf diseases. The classification of results accuracy can be achieved is $90.98 \%$ and we are developing the new concepts or methods like a HIS transformation is applied to input image and uses the image retrieval content based algorithm. we uses the various concepts or new algorithms for determining or classified the leaf disease. Using image retrieval algorithm feature extraction deals with size, shapes, colors and various spot detected. Finally the classification is done by matching the type of disease found that particular captured images. Plants assume an imperative part in the cycle of nature. The quantity of plant species is assessed to be around 400,000 however there still exist numerous species which are yet unclassified or obscure. Along these lines, plant ID is a critical and testing assignment. With the quick advance of data innovations, many works have been devoted to applying the advances of example acknowledgment and picture handling to plant distinguishing proof. Since leaves are the organ of plants and their shapes fluctuate between various species, the leaf shape gives profitable data to plant recognizable proof. Cell phones are broadly utilized gadgets around. Android, Windows Mobile, and the phone, cell phones are diverse brands which have changed the way we take a gander at versatile figuring. Numerous applications like recreations, long range informal communication, and bank exchanges are utilized on portable today. Today, everybody is utilizing cell phones, including the ranchers. Prologue to Information and Communication Technologies (ICT) has a vital part in everyday existence of ranchers.

Farming segment contributes in day by day needs of populace in India and is principle spine of GDP of Indian Economy. Ranchers are the primary component of Agriculture. Agriculturists are not ready to adapt up to confusions happening because of yield maladies. They need to rely on upon Plant Biologist to determine these issues. Looking at the plant influenced by infection through a Plant Biologist physically is a tedious procedure. Plant influenced by the infection is not analysed inside time then it can influence the nature of the plant.

A System can be given which can automatically get huge components of the plant influenced by malady and registering the transferred infected plant picture. It will effortlessly assist the Plant Biologist with diagnosing the infection of plant and give the agriculturists to take starting careful steps. Recognizing the centrality and strength of Agriculture part, System in light of Content Based Image Retrieval procedures. 
IARJSET

\section{PRESENT SYSTEM}

An Images form important data and information in biological sciences. Plant diseases have turned into a dilemma as it can cause significant reduction in both quality and quantity of agricultural products. Automatic detection of plant diseases is an essential research topic as it may prove benefits in monitoring large fields of crops, and thus automatically detect the symptoms of diseases as soon as they appear on plant leaves. The proposed system is a software solution for automatic detection and computation of texture statistics for plant leaf diseases.Image retrieval system search collection of images based on features that can be extracted from the image files. Images are searched from large logical image database. The logical image representation in image databases system is based on different data modules.

\section{RELATED WORK}

CBIR methods works uniquely in contrast to the conventional content base framework. Pictures put away in a group are separated and afterward components of those pictures are utilized for examination. Components of the pictures are consequently removed [4]. CBIR System for the most part utilize shading, shape and surface as their fundamental components so they work on level one which is at low level. Conventional framework takes inquiry from client by taking contribution as picture while a few frameworks offer additional choices to the client, for example, palette or portray input. Next stride framework contrasts the inquiry picture and put away picture and whose element values coordinates intently, those pictures are appeared to the client. Principle recovery sorts for picture recovery are clarified underneath.

\section{A. Shading Retrieval:}

Strategies for getting data from the picture on premise of shading have been clarified in different ways. Be that as it may, the greater part of the techniques is varieties of the fundamental thought of shading recovery [5]. At the point when a picture is utilized for correlation, it is initially handled and shading histogram is gotten from the picture, it demonstrates the extent of hues in every pixel of the picture. Shading histogram [6] got from picture is put away in database. At the point when shading histogram is computed, client can determine the extent of hues on information picture at inquiry time. Pictures whose shading histogram coordinates intimately with inquiry picture are considered. Swain and Ballard were the first to created Histogram crossing point coordinating procedure which is presently normally utilized.

Improvement in coordinating strategies has given to utilize CBIR procedures in more mind boggling framework. Enhanced strategy of Swan and Ballard are right now utilized which incorporates aggregate shading histograms, district based shading questioning. Consequences of this strategies are enhanced then the past one.

\section{B. Surface Retrieval:}

Picture examination should be possible on the premise of surface likewise, however it may not be appear to be helpful. Surface correspondence can be utilized for separation amongst hues and territory of pictures. Surface similitude is finished by computing values from inquiry and picture put away in database. Parameter of versatile brilliance from the combine of pixel of two pictures is considered for examination. Qualities are computed on the premise of scale, level of complexity, directionality, periodicity for surface investigation. Gabor channel and fractals is another technique for surface investigation of picture. Surface examination is finished by submitting inquiry picture or by selecting surface from palette. Framework then considers those picture whose surface measures coordinate intimately with inquiry picture.

\section{Shape Retrieval}

Third procedure is to get the data on the picture utilizing shape recovery .Basic necessity to recover the property of picture is by their shape which is at the essential level of shape recovery system. As opposed to surface, shape iss a great characterized approach. There are surprising verification of many questions in nature is for the most part recognized by their shape. Numerous qualities of a question's shape (free of size) are prepared for each picture put away in the database. The Queries are replied by preparing the proportionate components for the question picture and acquiring those pictures whose elements about match with inquiry picture. Two vital sorts of shape highlight are normally utilized like worldwide elements as viewpoint proportion, circularity and minute invariants and neighbourhood includes assets of progressive limit portions.

\section{Algorithm steps: \\ 1. RGB picture securing}

2. Change over the info picture from RGB to HSI design.

3. Covering the green-pixels

4. Expulsion of veiled green pixels

5. Section the segments

6. Get the valuable sections

7. Registering the components utilizing shading co-event strategy

8. Assessment of surface measurements.

Shading Transformation Structure: First, the RGB pictures of leaves are changed over into Hue Saturation Intensity (HSI) shading space representation. The reason for the shading space is to encourage the determination of hues in some standard, for the most part acknowledged way. HSI (tint, immersion, power) shading model is a well known shading model since it depends on human discernment.

\section{IV.PROPOSED SYSTEM}

In proposed system, application provides the various captured image of the leaf is an input image. This system applies the content based image retrieval algorithm related 
IARJSET

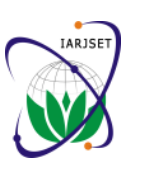

International Advanced Research Journal in Science, Engineering and Technology

National Conference on Innovative Applications and Research in Computer Science and Engineering (NCIARCSE-2017) AGTI's Dr. Daulatrao Aher College Engineering, Vidyanagar Extension, Karad

Vol. 4, Special Issue 4, January 2017

to that leaf images. The leaf images store to the database and then checking or matching the leaf images. And also compare leaf image with storing database images or data. On successfully exatact matching the captured leaf images with available data or images in database, then this application provide the solution to users or farmers.

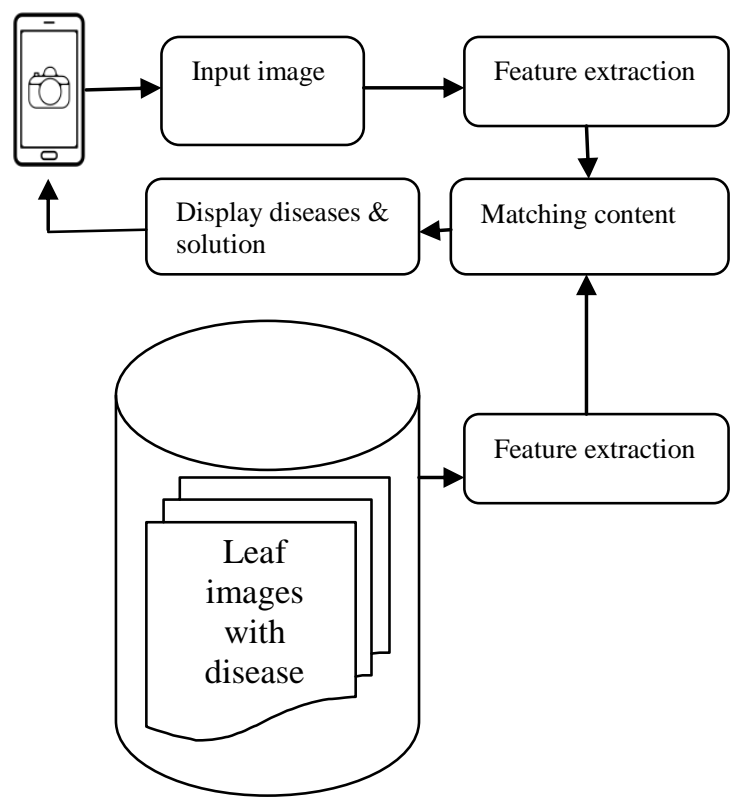

Fig.1. System Architecture

\subsection{Admin Training:}

In this module, necessary input image of the leaf sent to the system. The system applies number of steps to extract values for getting parameters for the images. This image with their parameter values is stored in the database. These function performed by the admin.

\subsection{Image retrieval:}

This module is part of the application is included in the web service for using on mobile phones. This module is used whenever user wants to discover any disease details about any leaf. Using this module, the user can submit the leaf image for its identification by the system.

\subsection{Pre-processing:}

Using this module, the image captured from the user's mobile is subjected to necessary pre-processing. In this method, image can be converted into standard binary format from other format like colour or gray scale. This method also used for the leaf is extracted for its comparison.

\subsection{Identification:}

In this process, the parameters of the leaf are extracted for its comparison with the ones stored in the database. Then the algorithms are applied on the pre-processed image for its comparison. The image which has matched with the ones stored in the database is displayed to the user for viewing further details about the leaf.

\subsection{Reply from system:}

In this module from system the user get result as a diseases and also get solution or prevention techniques.

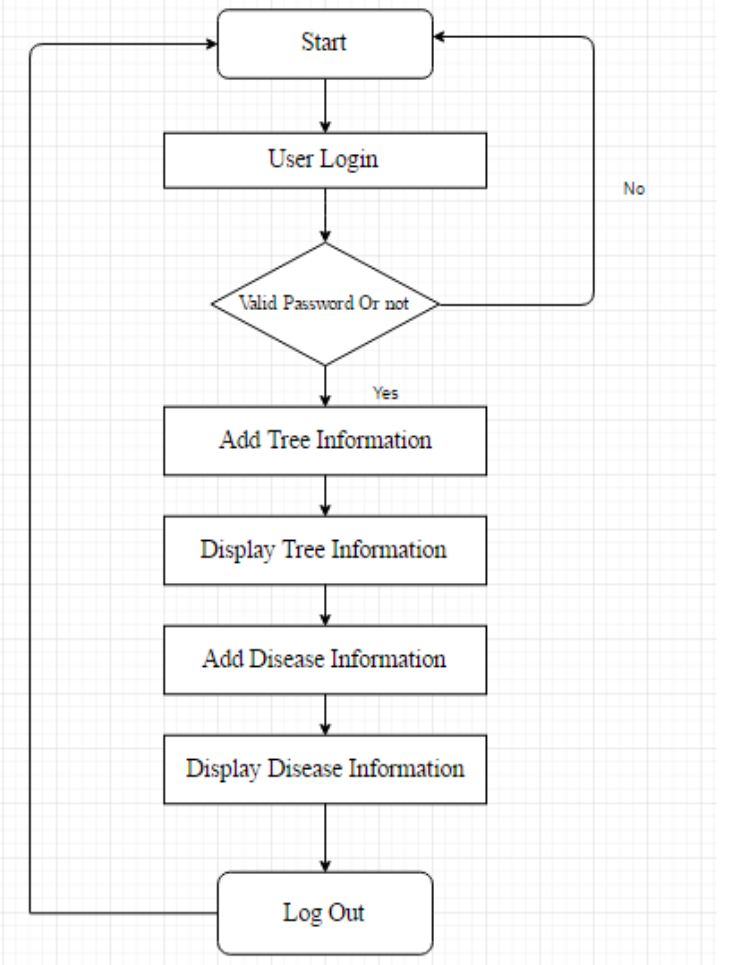

Fig. 2. System Flowchart
The main approach is to recognize the diseases. Speed and accuracy are the main characteristics of disease detection. Hence, the extension of this work will focus on developing the advanced algorithms for fast and accurate detection of leaves with disease. Utilizing CBIR strategies low level components (shading, shape, surface) of the picture are separated precisely and k-mean grouping strategy will expand exactness of the framework by characterizing the pictures with comparable elements together. In this way, exact outcomes can be given to client utilizing android cell phone. By using this project images search can be done using content based, colour has been taken as the property for searching, for efficient way of searching local histogram searching has been used, so it has advantages than global histogram, has been used for comparing the histograms of the images, considering all local histograms comparisons.

\section{ACKNOWLEDGMENT}

It is our privilege to acknowledge with deep sense of gratitude to our project guide Assistant Prof. and H.O.D Prof. Patil Ashish N. whose supervision, inspiration and valuable discussion has helped us tremendously to complete our project. Their guidance proved to be the most valuable to overcome all the hurdles in the 
IARJSET

fulfillment of this mega project on "Detection and

Classification of Plant Leaf Diseases".

\section{REFERENCES}

[1] Renuka Rajendra Kajale, "DETECTION \& RECOGNIZATION OF PLANT LEAF DISEASES USING IMAGE PROCESSING AND ANDROID O.S."s, International Journal of Engineering Research and General Science Volume 3, Issue 2, Part 2, March-April, 2015.

[2] Kshitij Fulsoundar, "DETECTION AND CLASSIFICATION OF PLANT LEAF DISEASES”, International Journal of Engineering Research and General Science Volume 2, Issue 6, OctoberNovember, 2014.

[3] S. Ananthi*, S. Vishnu Varthini*, "DETECTION AND CLASSIFICATION OF PLANT LEAF DISEASES", Volume 2, Issue 2 (February 2012) ISSN: 2249-3905.

[4] Rong Wang, Chong Li, "An Image Retrieval System Based on Color Features ", Wei Li College Of Policing information engineering people's public security University of China, 2013.

[5] Chesti Altaff Hussain1, Dr. D. Venkata Rao2, T. Praveen "Color histogram based Image Retrieval". Hussain, et al., International Journal of Advanced Engineering Technology.

[6] N.Valliammal and Dr.S.N.Geethalakshmi "A Hybrid Method for Enhancement of Plant Leaf Recognition". 